\title{
Experimental determination of zinc isotopic fractionation between aqueous fluids and silicate magmas
}

\author{
HAIHAO GUO ${ }^{1}$, YING XIA ${ }^{2}$, FEI WU ${ }^{3}$ AND FANG \\ HUANG $^{4}$
}

${ }^{1}$ Univ. Orléans, CNRS, BRGM, ISTO, UMR 7327, F-45071, Orléans, France

${ }^{2}$ University of Science and Technology of China

${ }^{3}$ China University of Geosciences

${ }^{4}$ CAS Key Laboratory of Crust-Mantle Materials and

Environments, School of Earth and Space Sciences, University

of Science and Technology of China

Presenting Author: haihaoguo49@gmail.com

Zinc, as a chalcophile and incompatible metal, and its isotopes have been wildly applied to study the magma derived fluids and magma degassing processes. However, zinc isotopic fractionation between aqueous fluids and silicate magmas has not been well constrained. Here we experimentally determined $\mathrm{Zn}$ isotopic fractionation between fluids and magmas reveals aqueous fluids to be isotopically heavier than the coexisting silicate magmas. $\mathrm{Zn}$ isotopic fractionation between aqueous fluids and silicate magmas $\left(\Delta^{66} \mathrm{Zn}_{\text {fluid-magma }}=\delta^{66} \mathrm{Zn}_{\text {fluid }}-\delta^{66} \mathrm{Zn}\right.$ magma) positively corresponds with the molar ratio of $\mathrm{Al} /(\mathrm{K}+\mathrm{Ca}+\mathrm{Fe})$ in the bulk magmas, rather than the temperature and fluid compositions. Our data therefore show the heavier $\mathrm{Zn}$ in the fluids exsolved from magmas may account for the higher $\delta^{66} \mathrm{Zn}$ values of pegmatites and high-silica granitic rocks. Moreover, magmatic fluids involvement explains the highly variations and extreme heavy $\mathrm{Zn}$ isotopic signatures of fumaroles, thermal spring waters and seafloor hydrothermal fluids. Therefore, $\mathrm{Zn}$ isotope may act as a potential indicator to trace fluid activities. 